\title{
The Effect of Teaching Mathematical Problems Solving Through Using Mobile Learning on the Seventh Grade Students' Ability to Solve them in Jordan
}

\author{
https://doi.org/10.3991/ijim.v12i3.8713 \\ Mohammad Ahmad Al-Khateeb \\ The Hashemite University, Zarqa, Jordan \\ mkm7879@hu.edu.jo
}

\begin{abstract}
The study aimed to probe the effect of solving mathematical problems through using Mobile Learning (ML) on the seventh grade students' ability to solve them in Jordan. The study sample consisted of fifty-four (54) students of seventh basic grade in Zarqa in Jordan who were divided into two groups randomly: experimental group which included twenty-six (26) students who were taught through using mobile learning methodology and control group which consisted of twenty-eight (28) students who were taught through using the traditional ways of teaching. Mathematical problem solving test were prepared which were verified to check their validity and reliability. In general, the results related to problem solving and its dimensions revealed the understanding and reading of the problem, setting forth a plan for solving and implementing it as well as revising the solution). The students of the experimental group were taught by using mobile learning methodology were more excellent than their counterparts in the control group who were taught through using traditional teaching.
\end{abstract}

Keywords — mobile learning, problem solving

\section{Introduction}

The enhancement of learners' ability to solve problems is an essential goal of mathematics teaching of the various educational stages; therefore, the importance of mathematical problem solving has emerged through many calls raised by reports issued by many national, regional and international bodies. In a report issued by $\mathrm{Na}-$ tional Council of Teachers of Mathematics, USA, (NCTM, 2000) the need to focus on solving math problems had been emphasized and considered a key hub for mathematics teaching programs, and a teaching standard for the various classes. The National Council of Teachers of Mathematics also gave mathematics supervisors (NCSM, 2000) the core mathematical components of the twentieth century, and stated solving problems in its forefront.

Although many of the educators agreed upon the need to teach solve problems to students as a goal of mathematics teaching, but we do not notice practical translation 
of such need since we found that it was limited only to improve the arithmetical skills and that captured the full attention by those who teach mathematics in the classroom. Problems solving involved skills which transcended mathematical skills and as a result of concentrating more on the arithmetical skills more than other problemsolving skills students became unable to solve mathematical problems (Al-Shari, 2009; Barak \& Mesika, 2007; Al-Natheer, 2009; Bernadette, 2010). Consequently, students' inability in solving mathematical problems is a global phenomenon, and the results of research indicated that the most important difficulties faced by students in solving mathematical problems was due to lack of understanding of the problem in terms of their ability to analyze the problem and identify the given and required, recognize the meaning of the vocabularies, as well as students didn't use of any strategy or steps that explain the solution, and most of them used trial and error strategy but in an unorganized way, thus they failed to reach the solution as well as they lacked of awareness reasonableness of the of their findings that they arrived at (Bautista, Mitchelmore \& Mulligan, 2009; Krulik Rudnick, 2005). After reviewing many studies by Ruwaished and Ajami (2009) which were carried out to address mathematical problem solving, they found that the main difficulties faced by students in problemsolving skills was the ways teachers used to teach them; since teachers depended on using traditional teaching method which basically focused on indoctrination and direct application of the mathematical rules so that students' role was limited to the simulation of method used by the teacher to reach at a mathematical solution.

The massive advances in communications and information technologies and the spread of the electronic knowledge among school and university students has led to the emergence of new forms of education systems (Patti, 2010), and M-learning is new form of the educational process innovations because of its features, benefits and the support for students and the educational process. M-learning also is the most essential component that countries depend on in their institutions in building their future in such electronic era (Paul, 2009). M-learning was defined by (Attewell, 2005) as a "the delivery systems of curriculum via mobile communication devices through the use of local wireless networks or satellite to deliver information outside of the classroom in order to meet the changing circumstances in education that were affected by the globalization phenomenon."

As viewed by (Salem, 2006; Kinshuk, 2008) that M-learning would be the best and most widespread way of education and training in the near future to solve the problem of the huge number of students, where M-learning could be used have access to education on a large scale for the various segments of society, regardless of gender, race, time and place due to the characteristics M-learning that made it quite different experience from traditional learning in a classroom where all educational activities that based on the time and place, as well as it differed from other distance learning forms because it provided rich environment of the tools and facilities. The most important features of M-leaning were specified by (Brown, 2008; Edward, 2005) as follows: Mlearning could be presented all the time and everywhere through providing access to information which was previously impossible to access by multiple classes of society because time, place, and financial cost to buy desktop and laptops computers or phones subscriptions to connect to the network didn't form obstacles to groups that 
couldn't afford to gain access and acquisition of knowledge. M-learning also allowed learner to communicate rapidly with the international information network. Mlearning facilitated the exchange of messages among learners and teachers via Short Message Service (SMS) or Multimedia Messaging Service (MMS) messages, it also facilitated e-files and e-books sharing among learners, as well as the cost of this technology was relatively low since most mobile digital devices didn't cost too much to buy compared with desktop computers.

M-learning has been employed in teaching some subjects in various students' educational stages and it has proven its successfulness in improving the teaching-learning process as many studies which focused on M-learning as new learning technique had confirmed. In a study carried out by Dahir and Baiya'a (2009), which aimed to know the potentials offered by M-learning for students of mathematics in terms of learning strategies. That study also examined the mathematical processes and elements that encourage work through using M-learning in students' active learning that had been supported by teachers in schools who went through that experience. It was also found that the surrounding of the mobile phone provides a rich learning context for students of mathematics, inside and outside the classroom. Additionally, in the study conducted by (Yerushalmy \& Botzer, 2009), the researchers tried to know the extent of female university students' use of mobile phones in learning mathematics. The researchers found that the mobile phone surroundings helped students in enriching their mathematical knowledge and one of the most important factors that helped in achieving that result was the link between the real motion issues and abstract mathematical models.

Therefore, the problem of the study was specified by students' inability to solve mathematical problems as well as the shortage of studies which addressed the use of M-learning in mathematical teaching-learning process, thus there was an urgent need to examine this domain to know the effect of teaching mathematical problem solving through using M-learning on seventh grade students' ability to solve such problems in Jordan.

\subsection{The problem of the study}

Because of the increased interest in employing technological innovations to improve the teaching-learning process of mathematics and the importance of mathematical problem solving skills, this study focused on the following main following question: What is the effect of the teaching mathematical problem solving through using M-learning on students' ability to solve them in general and each skill separately (reading and understand the problem, developing a plan and implementing it as well as reviewing the solution)?

\subsection{Research Focus}

The study aimed to know the effect of solving mathematical problems through using Mobile Learning (ML) on the seventh grade students' ability to solve such problems in Jordan. 


\section{$2 \quad$ Methodology of Research}

\subsection{General Background of Research}

Semi-empirical methodology was used in this study to find out the effect of the independent variable i.e. method of teaching (traditional or mobile learning) on the dependant variable represent in (mathematical problem solving skills).

\subsection{Sample of Research}

Many schools of the Directorate of Education of First Zarqa Area were visited to talk with school principals and teachers in those schools about the possibility of cooperation with the researcher and the study sample was chosen through specification to ensure the collaboration of the principal and the teacher of mathematics who was directly related with the implementation of the study effectively. Therefore, Amoria School was chosen which had three seventh basic grade sections. Two of those classes were chosen randomly to form the study sample and they were divided into two groups (experimental group: 26 students) and (control group which consisted of 28 students) randomly.

The four tests related to mathematical problem solving were applied on the study sample and Wilks' Lambda value principle was calculated and the results are demonstrated in table (1).

Table 1. Wilks' Lambda value principle of problem solving skills testing

\begin{tabular}{|l|c|c|c|c|}
\hline & $\boldsymbol{V}$ & $\boldsymbol{F}$ & $\boldsymbol{d f}$ & Sig \\
\hline Wilks' Lambda value principle group & 0.93 & 1.19 & 49 & 0.32 \\
\hline
\end{tabular}

Table (1) showed that there wasn't any statistical significant difference at $(\alpha=$ $0.05)$ between the arithmetic average of the scores of students in the experimental group, and the arithmetic average of the scores of their counterparts in control group concerning of testing mathematical problem solving skills indicating that equality of the two study groups in solving mathematical problems skills in the pre-application.

\subsection{Instrument and Procedures}

First: M-learning content design. Dick and Carey model, 1985 and SMSE model related to mobile learning content were combined which consisted of the following stages:
1. Scenario
2. Message
3. Synchronization
4. Evaluation 
In light of the learning program, nature in the study which combined these stages within Dick and Carey model in order to produce and develop learning materials the model used in this study was shown in figure (1).

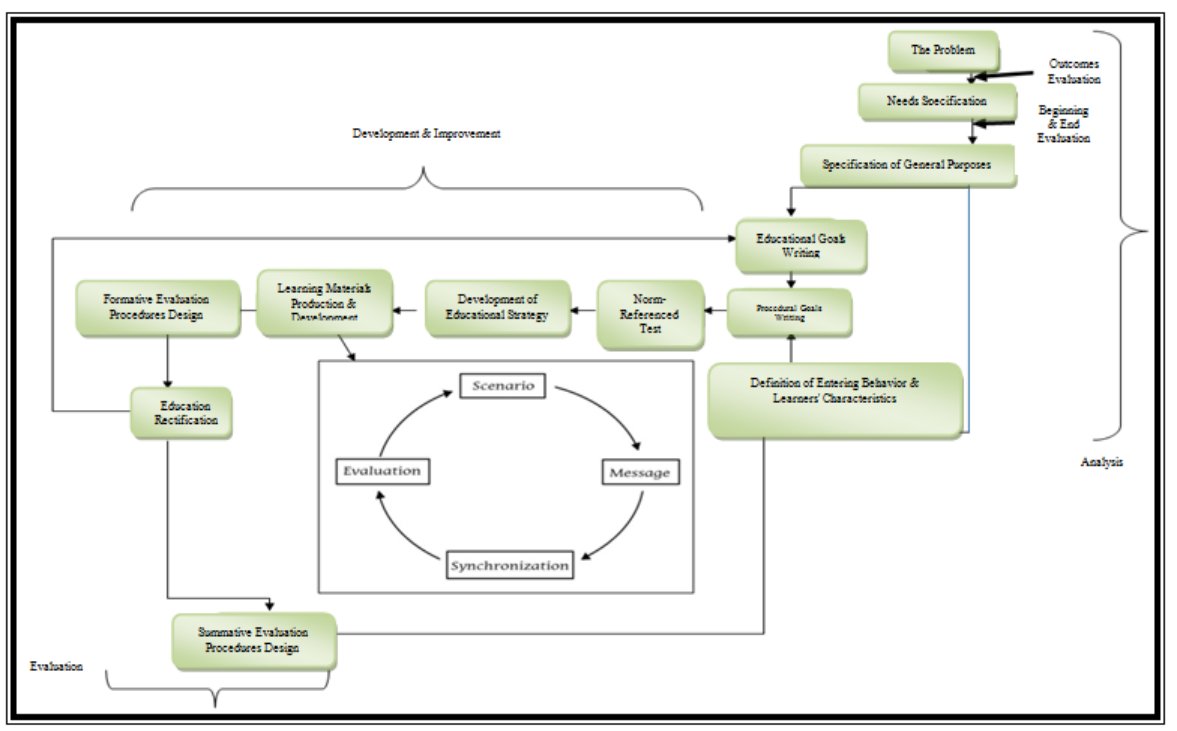

Fig. 1. The suggested learning model design

Steps of the learning design according to the suggested model

1. Goals writing and analysis stage: The researcher analyzed the content of equations and inequalities as well as setting forth a list of the learning goals, which amounted to 19 goals.

2. Development and improvement stage: In this stage SMSE model was used and benefited from in the learning design stage and the four steps of the aforementioned model were used:

First: Scenario preparation. The scenario of each lesson in the unit addressed two problems and each one of those problems contained the following elements: presenting the problem, asking question about the problem to ensure students' understanding; define data and information; specify what was required, present a way for reaching at the solution; implementing the solution as well as to revise the solution.

Based on the aforementioned the scientific content was selected and organized of some of the practical aspects on the subject of equations and inequalities in the initially, and they were presented to specialists experts in the field of educational technology to know their viewpoints about the extent to which the scientific content of the educational objectives were realized as well as the accuracy of the scientific content formulation of practical aspects of the subject of equations and inequalities. After completing the proposed amendments to the scientific content as agreed upon by the 
arbitrators, the scientific content in was prepared, so as to use it when building the text of mobile learning (scenario).

The methods of presenting scientific material display in the mobile learning varied since some of them contained only the texts, while others contain text and images, others contained multiple-choice questions, and some contained text and some video clips when needed, and a spreadsheet. The educational material was basically used in written form so that the student from shifted from one screen to another by pressing "Next" button and previous screen could be viewed again clicking "Previous" button and in any time the student could browse exam screen by clicking "?" and navigation bar which contained shifting buttons in the top and bottom of the screen as well as in all of the other screens

The interaction between student and scientific material started when receiving an SMS on his/her mobile phone which included the required lesson task then the student run the lesson to show its mobile content on his/her mobile phone, after that the student moved from one screen to another through using navigation bar.

The first screen of the lesson presented the first problem in the form of a text accompanied by an expressive image of the problem. Presentation of the problem was followed by several screens containing questions that helped student to analyze and understand the problem, and these questions are multiple-choice questions which the learner interacted with to choose the correct answer by selecting browsing buttons or associated pointing tool in his/her mobile phone. Each question is accompanied by strengthening text for correct answers and wrong answers. After completing the questions, results were gathered in the data screen which was followed by a screen containing the required task. Then text screens were followed images or tables to display and implement the solution plan of the problem. Eventually, and after viewing problems and interacting with them then the students could access to the exam screens, which contained the number of multiple-choice questions which they interacted with by choosing the correct answer, and upon completion of the test the student's overall result showed whether they performed successfully or unsuccessfully a long with providing appropriate reinforcement text for each case.

Second: Messages Preparation. Study units were divided into seven lessons and each of them consisted of many frameworks so that each one encompassed the following:

1. Instructions framework: It contained instructions for students about going through the lessons as well as explaining the functions of the navigation bar.

2. Problem presentation framework: it presented the problem of the subject matter of the lesson verbally a long with its relevant expressive image.

3. Problem understanding framework: It consisted of a graphical shape indicating the organized steps for solving the problem. This framework were followed by sub-frameworks which included question that were asked to ensure students' understanding of the problem and those questions were followed by instant reinforcement for both correct and wrong answers.

4. Solution plan framework. It explained the plan or method that would be used to solve the problem. 
5. Solution implementation framework: It contained steps for implementing the solution and by using substitution in equations until reaching to result of a solution to the problem by following the previously defined solution plan.

6. Solution revision and expansion of its scope framework: in this framework the result was verified from solving the problem and the scope of the solution was done to generalize it to other problems.

7. Examination framework: It consisted of evaluative questions in the subject matter of the lesson and contained a number of multiple-choice questions.

8. Feedback framework: It presented the result of the test, showed a congratulation phase of successful students and in case of their failure it informed them to run the lesson again.

Third: Synchronization .After completing lesson content development then it was uploaded on the connection system which followed Mobile Delivery and Tracking System (MDTS) and the researcher participated in this service, therefore he had registered and created accounts for students who made up the sample. SMSs were sent to students' mobile phones and each message contained the lesson route which could be accessed through an Internet connection by using a mobile phone so that the scientific material of the lesson could be delivered. The system tracked students' activity.

- Synchronous presentation: The researcher developed a problem for each lesson to present them to the students in the class period, after explaining the lesson as usual then researcher sent a problem link for students and asked them to resolve it through their mobile phones, at a time when it was uploaded on a tracking system to extract the results of problem solutions instantly, and that way represented synchronous presentation of the problem solving. The researcher then extracted the results of the answer to that activity. The tracking system enable the researcher to extract from the pertaining results of specific content which was accompanied by a diagram that showed the number of participants in the training, and their results. Additionally, there was screen which included content information that the student had to deal and review, and a report was presented on the test, which the student operated, as well as the number of reviewed pages. Moreover, there was screen that showed the results of the review exercise which contained questions to ask to clarify the problems and help to understand them.

- Asynchronous presentation: Students could browse mobile content nonsynchronously whenever they prefer but the tracking system monitored and registered their activities. The researcher could access to the system to extract results and statistics which helped him evaluate the learning process so that he could realize the number and times of student's access to lessons as well as the results of solving the tests of each lesson.

Fourth: Evaluation \& redesign. At this stage the results lessons tests displayed asynchronously and exercises that were being operated simultaneously were analyzed, and students' errors in problem solving could be addressed or to correct a wrong concept. Treatment of such problems normally synchronized with the teacher's re- explanation of the problems directly to students who faced difficulty in solving such prob- 
lems. At this stage, the whole process was also evaluated through using statistics which were obtained through the delivery system and followed mobile content to decide the extent of the success of the proposed technological concept of mobile learning and achievement of its desired goals and objectives.

After having the initial prescription of the suggest mobile learning technology, the researcher conducted formative assessment of the educational program screens to ensure its integrity and validity for the final experimentation which represented in the following

1. Initial version of the suggested mobile learning technology was presented to experts in the field of education technology and methods of teaching mathematics to ensure the suitability of the scientific material content of the educational program that based on mobile learning; activities and exercises appropriateness with learners' characteristics and abilities; the integrity accuracy and recentness of the scientific content of the program; aptness and quality of printed, drawn and photographed elements; cohesion and integration among the elements of the training program based on mobile learning; observations of relevant standards to construct and design educational programs based on mobile learning to achieve the desired goals.

2. The necessary amendments were done and the researcher carried out an exploratory experience on a small sample of 12 students from outside the study sample. During the experimentation process, the researcher monitored a range of observations about the proposed perception of mobile learning. As well as taking into account the group of views and proposals, amendments had been made related to the order of subjects, fonts, and content elements differentiation, and the size of the illustrative images. Then the researcher prepared the final version of the program and became ready for use.

Fifth: The implementation of the suggested educational program. At this step, the researcher implemented of the proposed perception proposed learning mobile technology in its final version on the seventh grade students, according to the following steps:

1. Training of the experimental group's teacher on teaching based on mobile learning.

2. Implementing the study which started during the first month of May of the second semester of the scholastic year 2015/2016. The teaching of the equations and inequalities unit took 5 weeks, by (5) class periods per week, where the experimental group was taught through using mobile learning, the control group was taught by while the using the traditional method of teaching with same subjects and number of class periods. Students of both experimental and control groups were taught by the same teacher.

Second: Examination of mathematical problem solving skills. Examination of mathematical problem solving skills aims to evaluate and measure seventh grade students' ability in mathematical problem solving. After reviewing studies which addressed problem solving skills such as the studies conducted by (Bernadette, 2010; 
Barak \& Mesika, 2007; Al-Natheer, 2009), the researcher prepared the exam to test students' mathematical problem solving skills as follows:

- Mathematical problem understanding and analysis skills test which consisted of (18) items distributed over six main questions.

- Setting forth and implementing solution plans skills test which consisted of (14) items distributed over two main questions.

- Reviewing solutions skills test to ensure its correctness which consisted of (6) items distributed over two main questions.

- The test focused on mathematical problem solving skills in general which consisted of (4) problems.

The problems of the four tests were prepared putting into consideration the mathematics subject of seventh grade students in terms of their mathematical contents. Since multiple-choice and essay questions were used rubric was designed for marks of the tests so that one (1) mark was allocated for each item in multiple-choice questions and four (4) marks for essay questions (mathematical problem) distributed over solution skills as follows: one mark was designated for problem understanding and analysis skill, setting solution plan skill, implementation of the plan skill, solution revision to ensure the correctness of the answer respectively.

The validity of the four tests were verified through presenting them a group of specialized in the domain of this type of learning to provide their viewpoints about tests in terms the item scientific accuracy, its formulation and clarity to measure each skill and based on the arbitrators' observations the questions of the tests were amended. To verify the stability of the four tests they were applied on an expletory sample of (30) seventh grade students from outside the experimental and control samples and stability coefficient was calculated through using Cronbach's alpha coefficient for each test separately which was: $[(0.81),(0.83),(0.79),(0.85)]$ and for the four tests as whole the stability coefficient was $(0.87)$ and each of aforementioned values were acceptable in such case so that tests took their final form.

\section{$3 \quad$ Results of Research and Discussion and Conclusions}

The results of the statistical analysis demonstrated the following:

Question One: What is the effect of teaching mathematical problem solving through using M-learning on students' ability to solve them in general and each skill separately (reading and understand the problem, developing a plan and implementing it as well as reviewing the solution?

To answer this question, arithmetic means and standard deviations were calculated of participating students' performance of the in the study concerning problem solving skill and its relevant skills according to the group as indicated in table 2 . 
Table 2. Arithmetic means and standard deviations of the study sample's performance related to mathematical problem solving skills

\begin{tabular}{|l|l|c|c|c|}
\hline \multicolumn{1}{|c|}{ Skills } & \multicolumn{1}{c|}{ Group } & Number & mean & SD \\
& & & & \\
\hline \multirow{2}{*}{$\begin{array}{l}\text { Mathematical problem under- } \\
\text { standing and analysis }\end{array}$} & Experimental & 26 & 14.58 & 1.30 \\
\cline { 2 - 5 } & Control & 28 & 9.57 & 1.83 \\
\hline \multirow{2}{*}{$\begin{array}{l}\text { Putting and implementing a } \\
\text { solution plan }\end{array}$} & Experimental & 26 & 11.62 & 1.13 \\
\cline { 2 - 5 } & Control & 28 & 8.21 & 1.34 \\
\hline \multirow{2}{*}{$\begin{array}{l}\text { Solution revision and making sure } \\
\text { of its correctness }\end{array}$} & Experimental & 26 & 5.08 & 0.74 \\
\cline { 2 - 5 } & Control & 28 & 2.36 & 1.16 \\
\hline \multirow{2}{*}{ Mathematical problem solving } & Experimental & 28 & 13.27 & 1.82 \\
\cline { 2 - 5 } & Control & 8.29 & 2.16 \\
\hline
\end{tabular}

The table (2) showed that there were of apparent differences in the arithmetic mean of the scores of the experimental group students and their counterparts in the control group concerning problem-solving and the sub-skills test and in favor of the experimental group that was taught using learning mobile, and to test those differences between the arithmetic means Wilkes' principle value calculated at $(0.14)$ and F-value corresponded to (78.17) and statistical significance was (0.00). Multivariate Analysis of Variance (MANOVA) was also used. Table (3) demonstrated the results of students' scores analysis in the two groups: experimental and the control groups related to problem solving test in general and each skill separately.

Table 3. Multivariate Analysis of Variance (MANOVA) of experimental and control groups students' scores in the post-application of problem solving test in general and each skill separately

\begin{tabular}{|c|l|c|c|c|c|c|c|}
\hline \multicolumn{1}{|c|}{ Skill } & Sum Sq & D.F. & MS & F-value & Sig. & Effect size \\
\hline \multirow{5}{*}{ Group } & $\begin{array}{l}\text { Mathematical problem under- } \\
\text { standing and analysis }\end{array}$ & 337.78 & 1 & 337.78 & 131.86 & 0.00 & 0.72 \\
\cline { 2 - 8 } & $\begin{array}{l}\text { Putting and implementing a } \\
\text { solution plan }\end{array}$ & 155.95 & 1 & 155.95 & 100.28 & 0.00 & 0.66 \\
\cline { 2 - 8 } & $\begin{array}{l}\text { Solution revision and making } \\
\text { sure of its correctness }\end{array}$ & 99.73 & 1 & 99.73 & 103.15 & 0.00 & 0.66 \\
\cline { 2 - 8 } & $\begin{array}{l}\text { Mathematical problem solving } \\
\text { Error }\end{array}$ & 334.82 & 1 & 334.82 & 83.37 & 0.00 & 0.62 \\
\hline & $\begin{array}{l}\text { Mathematical problem under- } \\
\text { standing and analysis }\end{array}$ & 133.20 & 52 & 2.56 & & & \\
\cline { 2 - 8 } & $\begin{array}{l}\text { Putting and implementing a } \\
\text { solution plan }\end{array}$ & 80.87 & 52 & 1.56 & & & \\
\hline & $\begin{array}{l}\text { Solution revision and making } \\
\text { sure of its correctness }\end{array}$ & 50.27 & 52 & 0.97 & & & \\
\cline { 2 - 8 } & \begin{tabular}{l} 
Mathematical problem solving \\
\cline { 1 - 7 }
\end{tabular} & 208.83 & 52 & 4.02 & & & \\
\hline
\end{tabular}


Table (2) showed there wasn't any significant statistical difference at $(\alpha=0.05)$ between the arithmetic mean of experimental group students' scores compared with their counterparts in the control group in the post application the mathematical problem solving skills test in general and each the skill separately, where the calculated Fvalue was: (131.86) (100.28) (103.15) and (83.37) respectively and statistical significance was $(0.00)$ with a high effect size for each of them, and this difference was in favor of the experimental group. In order to find out the direction of that difference and to know the impact of teaching method variable on problem-solving skills, the amended arithmetic means were calculated and the results were shown in table 4.

Table 4. Amended arithmetic means and Standard deviation of both experimental and control groups students' scores in post application of problem solving and skills test.

\begin{tabular}{|l|c|c|c|}
\hline \multicolumn{1}{|c|}{ Skills } & \multirow{2}{*}{ Group } & $\begin{array}{c}\text { Amended Arithmetic } \\
\text { mean }\end{array}$ & SD \\
\hline \multirow{2}{*}{ Mathematical problem understanding and analysis } & (M-Learning) & 14.58 & 0.31 \\
\cline { 2 - 4 } & Control & 9.57 & 0.30 \\
\hline \multirow{2}{*}{ Putting and implementing a solution plan } & (M-Learning) & 11.62 & 0.24 \\
\cline { 2 - 4 } & Control & 8.21 & 0.24 \\
\hline \multirow{2}{*}{ Solution revision and making sure of its correctness } & (M-Learning) & 5.08 & 0.19 \\
\cline { 2 - 4 } & Control & 2.36 & 0.19 \\
\hline \multirow{2}{*}{ Mathematical problem solving } & (M-Learning) & 13.27 & 0.39 \\
\cline { 2 - 4 } & Control & 8.29 & 0.38 \\
\hline
\end{tabular}

Table (4) showed that the amended arithmetic mean of the control group students' scores mathematical problem solving skills post-test on the of was: (9.57), (8.21), (2.36) and (8.29), whereas the amend arithmetic mean of the experimental group students' scores in test mathematical problem-solving skills post-test was (14.58), (11.62), (5.08) and (8:29) indicating a difference at (5.01), (3.41), (2.72) and (4.29) respectively which demonstrated that the difference was in favor of the experimental group students which was higher than their counterparts in the control group in the post-test result in mathematical problem solving skills.

That result was attributed to the way in which learning mobile technology design was made, most screens were designed to contain an explanation of the text, in addition to video images, which their presentation way accorded with written text, and that idea was consistent with the juxtaposition of spatial base when designing elearning programs, which stipulated the following: "Students learn when words and their accompanied images are adjoining on the screen, rather than when they are presented separately (Cynthia, 2010), and that result accorded with the results of the study carried out by (Keegan, 2005; Daher, 2009) which confirmed that the use of mobile learning would help considerably in establishing the theoretical information, increasing attainment, and these results were accorded with ones concluded in the study conducted by (Saipunidzam \& Shakirah, 2010; Shawn, 2010) which indicated a positive effect for the use of mobile learning technology.

The researcher also attributed that result to the potential of browsing mobile learning program such as moving backward or forward, that helped learners to carry out 
quick review of the information which they did not comprehend accurately, thus facilitating their access to a high level of achievement, and the use of backgrounds, colors and control tools, the screen design pattern that might attract students' attention of about the show and maintained it that helped in improving experimental groups students' achievement as well as the ability of mobile learning technology to provide instant feedback suitable for its learner responses for implicit tests, as well as the ability to change the shape and content of the feedback which helped learners' attainment of cognitive aspects. Furthermore, the effectiveness of the scientific content presentation through using learning mobile technology, and presented it within the program structurally (where learner was graded from the simple to complex, and from public to private, and to achieve a sub-goal within the program as a step to achieve the next target and so on, until the end of the program), which helped in forming learner's scalable cognitive and interconnected structure at the same time.

In addition to the mobile voting (polling) service that were used simultaneously in the class period so that the student had an access to link connecting that service via SMS so as to choose one of the correct answers to the problem and then the student could move to the results page to see the round sector, which represented statistics about answers that won more votes that explained to the teacher the extent of the student's comprehension and ability to solve the problem posed by using the correct strategy and break the barrier of shyness by hiding the identity of the student who provided the answer so that all students were motivated to participate and increase their inquisitiveness. The tracking system called Delivery and Tracking System (MDTS) was one of the most important characteristics of learning mobile, which gave the teacher a full report on student's activities inside the module, the period of time he spent since entering until he left as well as the number of times he entered the each module which showed student's immersion, interactions and enjoyment while watching e-martial more than once, making the learning stayed longer period of time also teacher would define the student's shortcomings specifically an in turn enabling the teacher to treat them face-to-face with the student and ensuring better learning outcomes. These findings were consistent with the results of many previous studies, such as: (Ruwaished \& Ajami, 2009; Saipunidzam \& Shakirah, 2010; Yerushalmy \& Botzer, 2009)

\subsection{Recommendations}

- Urging the necessity of using mobile learning as a means to mathematics teaching, using wireless systems in public education, mainly, and mobile phones because of their positive effects on improving teaching-learning process.

- Benefiting from all technologies provided by mobile sets that can be used for educational purposes including reading e-books, construction and formation applications as well as social networks tools.

- Strengthening collaboration ties among public and private educational institutions in the field of M-learning software production for various education stages. 


\subsection{Suggestions}

- Conducting more studies to know more about the effect of M-learning technology in teaching the various mathematical skills such as mathematical thinking and mathematical proof.

- Conducting more studies which address various school subjects and education stages other than those used in this study.

- Carrying over a study to develop mathematical problem solving skins through using other technological solutions.

- Conducting studies related to smart content engineering because it constitutes the next phase of education technological revolution which is led by mobile innovations and computer networks.

\section{$4 \quad$ References}

[1] Al-Natheer, M. (2009). Mathematical problem solving and mathematical patterns during solution and graphological characteristics of students majoring mathematics in teachers' colleges, Mathematics Education Journal, 36(12): 9-40.

[2] Al-Shari, D. (2009). Mathematics teachers' beliefs about mathematical problem solving and their relationship with some variables, Mathematics Education Journal, 3(12): 1-35.

[3] Attewell, J. (2005). Mobile Technologies and Learning, London: Learning and Skills Development Agency.

[4] Barak. M. \& Mesika. P. (2007). Teaching methods for inventive problem- solving in junior high school. Thinking Skills and Creativity. V2. 19- 29. https://doi.org/10.1016/j.tsc.20 06.10 .002

[5] Bautista, D., Mitchelmore, M. \& Mulligan, J. (2009). Factors influencing Filipino children's solutions to addition and subtraction word problems. Educational Psychology. 29(6): 729. https://doi.org/10.1080/01443410903254591

[6] Bernadette, E. (2010). Third grade students' challenges and strategies to solving mathematical word problems. M.A. dissertation, The University of Texas at El Paso, United States, Texas .

[7] Brown, L. (2008). Using Mobile Learning to Teach Reading. Dissertation Abstracts Doctor. Capella University

[8] Cynthia, M. (2010). Integrating Cell Phones into the Secondary Montessori Classroom. Doctoral Dissertation - of Walden University.

[9] Daher, W. (2009). Students' Perceptions of Learning Mathematics with Cellular Phones and Applets. International Journal of Emerging Technologies in learning, (1), 23-28. https://doi.org/10.3991/ijet.v4i1.686

[10] Dahir, W.\& Baiya'a, N. (2009). Elementary school students' learning characteristics of mathematics by the aid of mobile phone. Al-Qasimi Journal - Academic College of Education, Issue No. 13: 23-46.

[11] Dick, W. \& Carey, L., (1985). Systematic Design of Instruction, New York: Glenview Scott Foreman and Company, P.7

[12] Edward, S. (2005). Apply Mobile Technology in Foreign Language Learning, Yuhsun: Capella University.

[13] Keegan, D.(2005). The future of Learning: From eLearning to MLearning, available online at: http://learning.ericsson.net/ 22-9-2017 
Paper-The Effect of Teaching Mathematical Problems Solving Through Using Mobile Learning on ...

[14] Kinshuk, S., (2008). Adaptive Mobile learning, available on line at: http://www.elearning.edu.sa/forum/showthread.php?t=574. 10-8-2017

[15] Krulik, S. \& Rudnick, J. (2005). Problem Solving A Hand Book For Teachers. Second Edition. Massachusetts, Allyn and Bacon.

[16] National Council of Teachers of Mathematics (NCTM). (2000). Principle and Standards For School Mathematics. Reston, Va: NCTM

[17] NCSM (2010). Common Core State Standards. Retrieved at: http://www.mathedleadership.org/resources/index.html.(25/5/2017)

Patti, S, (2010). Getting Started With Mobile Learning (m-Learning). Santa Rosa: The eLearning Guild Research.

[18] Paul. W. (2009). Assessing Mobile Learning Effectiveness and Acceptance. Doctoral Dissertation, George Washington University .

[19] Ruwaished, N. \& Ajmi, A. (2009). The effectiveness of teaching some mathematical problems solving strategies on developing fifth grade students' achievement, mathematical understanding and perceptions towards mathematical problem solving in Kuwait. Journal of College of Education - Alexandria University. 19(3), 231-272.

[20] Saipunidzam, M. \& Shakirah, K., (2010). M- Learning: A New Paradigm of Learning Mathematics in Malaysia. International journal of computer science \& information Technology (IJCSIT). 2 (4): 23-50

[21] Salem, A. (2006). Mobile Learning: A new vision for learning through using wireless technologies. Published research in the Eight Scientific Conference of the Egyptian Society for Teaching Curricula and Methodologies during 25 - 24 .

[22] Shawn, W. (2010). Mobile learning: An analysis of student preferences and perceptions surrounding podcasting. Doctoral Dissertation, Houston University. UMI Number: 3411306

[23] Yerushalmy, M. \& Botzer, G. (2009). Teaching secondary mathematics in the mobile age in Zaslavsky, O. and Sullivan, P. (Eds.) Tasks for Secondary Mathematics Teacher Education.

\section{Author}

Mohammad Ahmad Al-Khateeb is with The Hashemite University, Zarqa, Jordan.

Article submitted 09 March 2018. Resubmitted 09 April 2018. Final acceptance 08 May 2018. Final version published as submitted by the author. 